\title{
SAPA ORANG TUA DENGAN PENGETAHUAN REMAJA TENTANG KESEHATAN REPRODUKSI REMAJA
}

\author{
Arum Dwi Anjani1), Sisca Dwi Puspita2) \\ ${ }^{2}$ The Study Program of Midwifery Faculty of Medicine Batam University \\ Email: arum.dwianjani05@univbatam.ac.id \\ ${ }^{2}$ The Study Program of Midwifery Faculty of Medicine Batam University \\ Email: siscadwipuspita31@gmail.com
}

\begin{abstract}
BackgraundThe cause of adolescents' inadequate knowledge about reproductive health is the lack of parental communication as the main source of information, especially in terms of sexuality and adolescent reproductive health. Based on the Indonesian Youth Reproductive Health Survey, adolescents claim to have friends who have had premarital sexual relations aged 14-19 years (women 34.7\%, men 30.9\%), ages 20-24 years old (women $48.6 \% \%$, male $46.5 \%$ ). This data shows that reproductive health problems among adolescents. Consequently, it will have a major influence on population growth and the future of the nation.

The purpose of this study was to see whether there was a relationship between parents and the knowledge of adolescents about adolescent reproductive health.

MethodsThis research is descriptive correlative, with a cross sectional approach. This research was conducted from February to August 2018 at SMP Negeri 28 Batam. The population in this study were all teenagers of class VII 255 students. Sampling with purposive sampling technique, a total sample of 156 respondents. The data was analyzed by Chi-Square analysis. Instruments applied questionnaires (questionnaire).

The results of the bivariate analysis were 156 teenagers who had less parental greetings with less knowledge as many as 37 respondents (23.7\%). The results of the bivariate test had a significant relationship between parental greetings with adolescent knowledge about adolescent reproductive health with the results of chi-square analysis $p$ value $=0,000$ smaller than the value of 0,05 .

Conclusion, there is a relationship between the parents' greetings and the knowledge of adolescents about adolescent reproductive health.

Suggestion that parents should increase more greetings with teenagers in order to develop teenagers' understanding of reproductive health so as to prevent adolescents from negative sexual behavior.
\end{abstract}

Keywords: Parents' Greetings, Youth Knowledge, Adolescent Reproductive Health.

\section{ABSTRAK}

Latar Belakang Penyebab kurangnya pengetahuan remaja tentang kesehatan reproduksi adalah kurangnya komunikasi orangtua sebagai sumber informasi pertama bagi remaja terutama dalam hal seksualitas dan kesehatan reproduksi remaja. Berdasarkan Survei Kesehatan Reproduksi Remaja Indonesia (SKRRI) remaja mengaku mempunyai teman yang pernah melakukan hubungan seksual pranikah usia 14-19 tahun (perempuan $34,7 \%$, laki-laki 30,9\%), usia 20-24 tahun (perempuan 48,6\%, laki-laki 46,5\%). Data ini menunjukan bahwa masalah kesehatan reproduksi dikalangan remaja jika diabaikan akan berpengaruh besar pada pertumbuhan penduduk dan masa depan bangsa.

Tujuan penelitian ini adalah untuk melihat apakah ada hubungan sapa orang tua dengan pengetahuan remaja tentang kesehatan reproduksi remaja.

Metode Penelitian ini bersifat deskriptif korelatif, dengan pendekatan cross sectional. Penelitian ini dilakukan pada bulan Februari sampai dengan Agustus 2018 di SMP Negeri 28 Batam. Populasi pada penelitian ini adalah seluruh remaja kelas VII 255 siswa. Pengambilan sampel dengan teknik purposive sampling, jumlah sampel 156 responden. Analisa yang digunakan yaitu analisa Chi-Square. Instrumen yang digunakan dengan menggunakan kuesinoner(angket).Hasil analisa bivariat yaitu dari 156 responden remaja yang memiliki sapa orang tua yang kurang dengan pengetahuan yang kurang sebanyak 37 responden $(23,7 \%)$.

Hasil uji bivariat terdapat hubungan yang signifikan antara sapa orang tua dengan pengetahuan remaja tentang kesehatan reproduksi remaja dengan hasil analisis chi-square $p$ value $=0,000$ lebih keci dari nilai a 0,05.

Kesimpulan ada hubungan antara sapa orang tua dengan pengetahuan remaja tentang kesehatan reproduksi remaja. 
Saran terhadap orang tua remaja hendaknya lebih meningkatkan lagi sapa dengan anak remaja agar pemahaman remaja mengenai kesehatan reproduksi meningkat sehingga dapat menghindarkan remaja dari perilaku seksual yang negatif.

Kata kunci : Sapa Orang Tua, Pengetahuan Remaja, Kesehatan Reproduksi Remaja.

\section{PENDAHULUAN}

Pemahaman tentang perkembangan seksual termasuk pemahaman tentang perilaku seksual remaja merupakan salah satu pemahaman yang penting untuk diketahui, sebab masa remaja merupakan masa peralihan dari perilaku seksual anak-anak menjadi perilaku seksual dewasa. Pemahaman remaja tentang seksualitas dan reproduksi masih amat kurang sampai saat ini. Kurangnya pemahaman ini amat jelas yaitu dengan adanya kebingungan pada sebagian kelompok remaja tentang apa yang boleh dilakukan dan apa yang tidak boleh dilakukan olehnya, antara lain boleh atau tidaknya melakukan pacaran, melakukan onani, menonton video pornografi atau ciuman dan ada beberapa kenyataan-kenyataan lain yang cukup membingungkan antara apa saja yang boleh dilakukan dan apa yang tidak boleh dilakukan (Soetjiningsih, 2010).

Hasil survei Curry (2011) di sekolah menengah umum USA menunjukkan kebanyakan siswa melontarkan kritik terhadap para orangtua karena tidak pernah memberikan informasi terkait seksualias dan kesehatan reproduksi terhadap anak-anaknya. Dua pertiga dari mereka sama sekali tidak mendapatkan informasi apapun, sedangkan sisanya hanya mendapat penerangan seadanya. Kurangnya komunikasi antara orangtua dengan anaknya yang disebabkan oleh orangtua yang sibuk bekerja untuk mencukupi kebutuhan keluarga dan kurang terbukanya orangtua terhadap anak dalam memberikan informasi tentang seksualitas. Tidak hanya orangtua saja yang harus bekerja, banyak pula anak remaja yang harus ikut bekerja untuk membantu mengurangi beban orangtua. Hal seperti itulah yang menyebabkan komunikasi antara orangtua dan anak semakin berkurang (Jumantik, 2016).

Seks pranikah atau seks bebas adalah masalah yang saat ini paling dominan terjadi di kalangan remaja kita, $1,3 \%$ remaja perempuan dan 4\% remaja laki-laki dari usia 15-19 tahun dan 1,4\% remaja perempuan dan $11 \%$ remaja laki-laki dari usia 20-24 tahun melakukan seks pranikah(UNFPA, 2012). Sekitar satu juta remaja pria $5 \%$ dan 200 ribu remaja wanita $1 \%$ secara terbuka menyatakan bahwa mereka pernah melakukan hubungan seksual (Kemenkes RI, 2013). Berdasarkan Survei
Kesehatan Reproduksi Remaja Indonesia (SKRRI) remaja mengaku mempunyai teman yang pernah melakukan hubungan seksual pranikah usia 14-19 tahun (perempuan $34,7 \%$, laki-laki 30,9\%), usia 20-24 tahun (perempuan 48,6 \%, laki-laki 46,5\%). Data ini menunjukan bahwa masalah kesehatan reproduksi dikalangan remaja jika diabaikan akan berpengaruh besar pada pertumbuhan penduduk dan masa depan bangsa (BKKBN, 2015).

Perilaku seks bebas dapat memicu munculnya masalah kesehatan seperti kehamilan yang tidak diinginkan, aborsi dan penyakit menular seksual termasuk HIVIAIDS. Pada tahun 2012 diketahui 15 juta perempuan remaja yang berusia 15-24 tahun melahirkan setiap tahun terutama di Negera berkembang, dan sebanyak $40 \%$ melakukan aborsi tidak aman, sedangkan 1 dari 20 remaja terinfeksi penyakit menular seksual setiap tahun dan setengah dari semua kasus telah terinfeksi HIV pada usia dibawah 25 tahun (UNFPA, 2012). Sedangkan menurut BKKBN (2011) Indonesia menduduki urutan ke 5 dari 10 negara dengan perempuan berusia 20-24 tahun yang melahirkan dibawah usia 18 tahun yaitu sebanyak 1.078.955 (Kemala, 2015). Menurut survei terakhir dari Badan Pusat Statistik (BPS) melalui Survei Demografi dan Kesehatan Indonesia (SDKI), tahun 2012 angka kehamilan remaja pada kelompok usia 15 - 19 tahun mencapai 48 dari 1.000 kehamilan (BKKBN, 2010). Sedangkan berdasarkan Susenas tahun 2015 angka kelahiran menurut umur (ASFR) 15-19 tahun di provinsi Kepulauan Riau dengan presentase $21,8 \%$, sedangkan Kota Batam sendiri memiliki presentase $15,3 \%$.

Berdasarkan data dari Pengadilan Agama Kota Batam tahun 2017, pengajuan dispensasi nikah anak di bawah umur pada 2017 mulai Januari sampai September meningkat menjadi 13 pengajuan. Padahal, pada 2016, hanya ada 9 pengajuan dispensasi nikah di bawah umur. Dari sejumlah pengajuan di tahun 2017 data yang diterima, usia dominan berada pada kisaran usia 16-18 tahun untuk laki-laki. Sedangkan untuk yang perempuan kisaran usia 14-15 tahun. Alasan permohonan dispensasi nikah di bawah umur, salah satunya adalah hubungan terhadap anak yang sudah sangat dekat dan atau karena hamil diluar nikah (Pengadilan Agama, 2017). 
Perilaku seksual remaja dipengaruhi oleh beberapa faktor yaitu faktor personal atau individu, faktor lingkungan dan faktor perilaku (Suryoputro et al., 2010). Faktor personal atau individu diantaranya pengetahuan tentang kesehatan seksual dan reproduksi yaitu mengenai HIVIAIDS, Penyakit Menular Seksual (PMS), aspek-aspek kesehatan reproduksi, sikap terhadap layanan kesehatan seksual dan reproduksi, kerentanan yang dirasakan terhadap resiko kesehatan reproduksi, gaya hidup, pengendalian diri, aktifitas sosial, rasa percaya diri dan variabel-variabel demografi. Sedangkan faktor lingkungan antara lain akses dan kontak dengan sumber-sumber informasi, sosial-budaya, nilai dan norma sebagai pendukung sosial untuk perilaku tertentu. Faktor perilaku antara lain gaya hidup seksual (orientasi seksual, pengalaman seksual, jumlah pasangan), peristiwa-peristiwa kesehatan (PMS, kehamilan, aborsi) dan penggunaan kondom serta alat kontrasepsi.

Pendidikan kesehatan tentang reproduksi di Indonesia lebih banyak diberikan pada siswa Sekolah Menengah Atas (SMA) daripada Sekolah Menengah Pertama (SMP), padahal jumlah siswa SMP lebih banyak daripada jumlah siswa SMA (Kemenkes RI, 2013). Remaja yang berada di tingkat awal sekolah menengah mempunyai risiko melakukan hubungan seksual di luar nikah baik disengaja ataupun tidak. Dikarenakan pada tahap ini remaja berada pada periode mencari identitas, menyebabkan remaja masih melakukan perubahanperubahan yang terjadi di dalam tubuhnya baik itu perubahan biologis, kognitif, dan sosio-emosional. Mereka mulai mengembangkan pikiran-pikiran baru dan mulai mencari tahu atas perubahan-perubahan yang terjadi dalam diri mereka. Oleh karena itu, masa yang paling tepat untuk memberikan pendidikan kesehatan reproduksi adalah pada masa remaja awal.

Badan kesehatan dunia (WHO, 2009)menekankan pentingnya pendidikan kesehatan reproduksi kepada kelompok remaja muda, yaitu kelompok usia 10 hingga 14 tahun. Usia ini adalah masa emas untuk membentuk dan mempersiapkan mereka untuk mengambil keputusan yang lebih bertanggung jawab terhadap kesehatan reproduksinya.

Penelitian ini bertujuan untuk mengetahui Hubungan Sapa Orang Tua dengan Pengetahuan Remaja tentang Kesehatan Reproduksi Remaja di SMP Negeri 28 Batam Kelurahan Belian Kecamatan Batam Kota Kota Batam Tahun 2018.

\section{METODE PENELITIAN}

Penelitian ini bersifat deskriptif korelatif, dengan pendekatan cross sectional, tempat penelitian di SMP Negeri 28 Batam pada bulan Februari sampai Agustus 2018. Populasi pada penelitian ini adalah remaja kelas VII. Pengambilan sampel dengan teknik purposive sampling, jumlah sampel sebanyak 156 responden. Pengambilan data menggunakan kuesioner. Data analisis menggunakan uji chi-square.

\section{HASIL DAN PEMBAHASAN}

Tabel 1 Distribusi frekuensi sapa orang tua pada anak remaja di SMP Negeri 28 Batam

Kelurahan Belian Kecamatan Batam Kota Kota Batam Tahun 2018

\begin{tabular}{cccc}
\hline No & Sapa orang tua & Frekuensi & $\%$ \\
\hline 1 & Baik & 113 & 72,4 \\
2 & Kurang & 43 & 27,6 \\
Total & & 156 & 100 \\
\hline
\end{tabular}

Tabel 2 Distribusi frekuensi pengetahuan remaja tentang kesehatan reproduksi remaja di SMP Negeri 28 Batam Kelurahan Belian Kecamatan Batam Kota Kota Batam Tahun 2018

\begin{tabular}{cccc}
\hline No & $\begin{array}{c}\text { Pengetahuan } \\
\text { Remaja }\end{array}$ & Frekuensi & $\%$ \\
\hline 1 & Baik & 94 & 60,3 \\
2 & Kurang & 62 & 39,7 \\
Total & & 156 & 100 \\
\hline
\end{tabular}

\section{Tabel 3 Hubungan sapa orang tua dengan pengetahuan remaja tentang kesehatan reproduksi remaja di SMP Negeri 28 Batam Kelurahan Belian Kecamatan Batam Kota Kota Batam Tahun 2018}

\begin{tabular}{cccccccc}
\hline \multirow{2}{*}{$\begin{array}{c}\text { Sapa Orang } \\
\text { Tua }\end{array}$} & \multicolumn{6}{c}{ Kurang } & \multicolumn{3}{c}{ Baik } & \multicolumn{2}{c}{ Total } & \multirow{2}{*}{$p$ value } \\
\cline { 2 - 7 } & $f$ & $\%$ & $f$ & $\%$ & \multicolumn{1}{c}{$f$} & $\%$ & \\
\hline Baik & 25 & 22,1 & 88 & 77,9 & 113 & 100 & \\
Kurang & 37 & 86,0 & 6 & 14,0 & 43 & 100 & 0,000 \\
\hline Total & 62 & 39,7 & 94 & 60,3 & 156 & 100 & \\
\hline
\end{tabular}




\section{PEMBAHASAN}

SMP Negeri 28 Batam mulai beroperasi pada tanggal 26 Februari 2006. Sejak beroperasi mulai tahun 2006, siswa-siswi SMP Negeri 28 Batam sempat merasakan pelaksanaan kegiatan Proses Belajar Mengajar (PBM) di dua Sekolah yang berbeda yaitu SD Negeri 06 Taman Raya dan SMA Negeri 3 Batam Kota. Hal ini disebabkan karena pada saat itu gedung sekolah belum diresmikan. Kegiatan PBM resmi berlangsung di atas gedung sendiri milik pemerintah Kota Batam, setelah dilakukannya peresmian gedung oleh Walikota Batam Drs. Ahmad Dahlan pada tanggal 26 Februari 2009.

Pada tahun ajaran 2017 berdasarkan data yang diperoleh dari Dinas Pendidikan, SMP Negeri 28 Batam tercatat memiliki siswa sebanyak 711 siswa dengan ruang belajar 18 Rombel, yang terdiri dari 255 siswa kelas VII dengan jumlah Rombel 6 , 230 siswa kelas VIII dengan jumlah Rombel 6, dan 220 siswa kelas XI dengan jumlah Rombel 6 .

Berdasarkan data yang di peroleh dari staff tata usaha sekolah, saat ini jumlah pegawai SMP Negeri 28 Batam berjumlah 34 pegawai yang terdiri dari 18 guru tetap Pegawai Negeri Sipil (PNS), 11 guru honorer pemerintah kota, 1 staff tata usaha, 2 staff perpustakaan, 2 karyawan umum yang terdiri dari 1 tenaga kebersihan dan 1 penjaga sekolah.

Menurut pemaparan guru bidang kesiswaan SMP Negeri 28 Batam pada tahun 2013 pernah terjadi peristiwa yang kurang pantas yang terjadi di lingkungan SMP Negeri 28 Batam. Sehingga hal tersebut dapat semakin memberikan representasi bagi orang tua maupun siswa dan siswi, bahwa saat ini sekolah bukan lagi menjadi tempat yang aman dan nyaman, terhadap anak. Image sekolah yang selama ini sebagai tempat mendidik para siswa dan siswi, agar memiliki karakter mental yang mampu bersaing, harus ternoda dengan banyaknya, aksi pelecehan yang dilakukan oleh oknum tenaga pengajar yang seharusnya menjadi panutan bagi siswa dan siswi. Hal ini selaras dengan wawancara dengan alumni siswi SMP Negeri 28 Batam, yang membenarkan bahwa pernah terjadi kasus demikian di SMP Negeri 28 Batam dan berdasarkan pemberitaan yang tersebar di media massa. Untuk mencegah hal tersebut dapat terulang kembali menurut pemaparan guru bagian kesiswaan, SMP Negeri 28 Batam akan lebih meningkatkan lagi pengetahuan remaja melalui berbagai kegiatan ekstrakulikuler salah satu nya adalah di bentuknya PIK-R dengan adanya usaha SMP Negeri 28 Batam dalam mengembangkan PIK-R di sekolah diharapkan dapat memberikan informasi yang benar bagi para siswa sebagai remaja serta menanamkan rasa tanggung jawab remaja terhadap alat reproduksinya.

Sekolah Menengah Pertama (disingkat SMP, bahasa Inggris: junior high school atau Middle School) merupakan jenjang pendidikan dasar pada pendidikan formal di Indonesia setelah lulus sekolah dasar (atau sederajat). Sekolah menengah pertama ditempuh dalam waktu 3 tahun, mulai dari kelas 7 sampai kelas 9 .

Berdasarkan penelitian yang telah dilakukan pada 156 remaja di SMP Negeri 28 Batam, hasil menunjukan bahwa remaja yang memiliki sapa orang tua yang baik sebanyak 113 responden $(72,4 \%)$, sedangkan jumlah remaja uang memiliki sapa orang tua yang kurang sebanyak 43 responden $(27,6 \%)$. Remaja dikatakan memiliki sapa orang tua yang baik apabila jumlah nilai dari kuesioner mencapai 16 sedangkan remaja yang dikatakan memiliki sapa orang tua yang kurang apabila jumlah nilai dari kuesioner $<13$. Remaja yang memiliki sapa orang tua baik disebabkan oleh komunikasi yang terjalin diantara mereka terbuka, adanya perhatian dan saling pengertian. Sedangkan remaja yang memiliki sapa orang tua yang kurang, hal ini dapat terjadi karena kurangnya keterbukaan, perhatian, dan tidak adanya timbal balik antara orang tua dengan anak, serta masih adanya pemikiran orang tua yang menganggap tabu jika membicarakan hal yang berkaitan dengan kesehatan reproduksi.

Hasil penelitian ini sesuai dengan teori yang mengatakan bahwa Komunikasi orang tua dengan anak remaja tentang kesehatan reproduksi yang efektif adalah proses penyampaian informasi yang dilandasi adanya kepercayaan, keterbukaan, dan dukungan yang positif pada anak agar anak dapat menerima dengan baik apa yang disampaikan oleh orang tua (Rahmat, 2010). Dalam hal ini komunikasi antara orang tua dan anak remaja dapat menghindarkan remaja dari perilaku seksual pranikah dikarenakan antara orang tua dengan anak terjalin hubungan atau komunikasi yang efektif sehingga memungkinkan terjadinya diskusi, sharing, dan pemecahan masalah secara bersama .

Hasil penelitian ini sesuai dengan hasill penelitian yang dilakukan oleh Rizka Kurniawati, Heny Setyowati ER, Mahmudah. "Hubungan Komunikasi Antara Orang Tua-Anak Remaja Dengan Kesehatan Reproduksi Dengan Perilaku Seks Pranikah Di SMA Negeri 1 Salaman Kabupaten Magelang Tahun 2010". Hasil penelitian menunjukan bahwa komunikasi yang efektif antara orang tua dengan anak remaja mempengaruhi pengetahuan remaja tersebut mengenai kesehatan reproduksi sehingga dapat menghindarkan remaja 
dari perilaku seksual pranikah. Penelitian ini juga dikemukaan oleh indrijati dalam kurniawati (2010) bahwa sikap seks pranikah remaja dapat di pengaruhi oleh kualitas komunikasi remaja dengan orang tua. Semakin efektif kualitasnya maka sikapnya semakin tidak mendukung (menolak/menjauh) terhadap perilaku seks pranikah atau sebaliknya, jika komunikasi orang tua dan remaja semakin menurun (tidak efektif) maka sikapnya akan mendukung terhadap perilaku seks pranikah.

Walaupun sapa orang tua pada remaja baik, orang tua harus tetap terus meningkatkan sapa (komunikasi) pada anak dalam pemberian informasi tentang kesehatan reproduksi dan tetap waspada terhadap kejahatan seksual karena maraknya kejadian pelecehan seksual, kekerasan seksual, dan pemerkosaan bahkan disertai pembunuhan, orang tua harus meningkatkan kewaspadaan dalam menjaga anak terutama anak remaja dimana masa remaja ini merupakan masa yang rentan karena masa dimana mereka mencari jati diri mereka. Untuk itu komunikasi antara orang tua khususnya ibu sebagai orang tua yang lebih dekat dengan anak, harus lebih di tingkatkan lagi agar dapat terjalin komunikasi yang efektif.

Berdasarkan hasil penelitian yang telah dilakukan pengetahuan remaja tentang kesehatan reproduksi remaja, remaja yang berpengetahuan baik tentang kesehatan reproduksi remaja di SMP Negeri 28 Batam sebanyak 94 responden $(60,3 \%)$ sedangkan remaja yang memiliki pengetahuan yang kurang 62 responden $(92,7 \%)$ dari total 156 responden.

Pengetahuan dipengaruhi oleh lingkungan dan salah satu unsur dalam lingkungan remaja disini adalah orang tua. Sapa orang tua pada anak remaja yang baik merupakan faktor yang membuat pengetahuan remaja tentang kesehatan reproduksi baik, karena remaja mendapatkan informasi mengenai kesehatan reproduksi yang cukup dari orang tuanya selain dari sumber informasi lain seperti teman sebaya, guru ataupun yang di dapat dari lingkungan sekolah. Remaja yang memiliki pemahaman secara benar dan proporsional tentang kesehatan reproduksi maka akan cenderung memahami resiko perilaku serta alternatif cara yang digunakan untuk menyalurkan dorongan seksual secara sehat dan bertanggung jawab. Menurut (Fitriani, 2015)salah satu faktor yang mempengaruhi pengetahuan seseorang adalah lingkungan dimana lingkungan adalah segala sesuatu yang ada di sekitar individu baik lingkungan fisik atau biologis, maupun sosial. Lingkungan berpengaruh terhadap proses masuknya pengetahuan ke dalam individu yang berada pada lingkungan tersebut. Hal tersebut terjadi karena adanya interaksi timbal balik yang akan direspon sebagai pengetahuan.

Hal ini sesuai dengan teori perkembangan sosial remaja, dimana orang tua yang memberikan bekal pengetahuan kesehatan reproduksi pada anak berarti memberikan pencegahan pada anak terhadap dampak negatif dari kesehatan reproduksi dalam menciptakan rasa nyaman, memberikan perlindungan agar tetap terhindar dari bahaya akan masa depannya sendiri. Apabila anak memperoleh informasi dengan benar dan wajar tentang kesehatan reproduksi khusunya seksualitas, maka anak tidak lagi mempunyai keinginan yang berlebihan untuk menyalurkan dorongan seksualnya dengan perilaku yang negatif (Gunarsa, 2010).

Berdasarkan hasil penelitian yang dilakukan pada siswa kelas VII di SMP Negeri 28 Batam dapat di simpulkan dari 156 responden, Dari tabel 5.3 dapat dilihat dari 94 responden $(60,3 \%)$ yang memiliki pengetahuan yang baik lebih banyak terdapat pada responden yang memiliki sapa orang tua yang baik 88 responden $(77,9 \%)$. Sedangkan pada responden yang memiliki sapa orang tua yang kurang sebanyak 37 responden $(86,0 \%)$.

Hasil analisis berdasarkan analisis statistik non parametik menggunakan uji chi-square, didapatkan $p$ value 0,000 lebih kecil dari nilai a 0,05 . Jadi nilai $p$ value kurang dari nilai a maka dinyatakan Ho ditolak, yang berarti terdapat hubungan antara sapa orang tua dengan pengetahuan remaja tentang kesehatan reproduksi remaja. Dengan demikian dapat disimpulkan bahwa terdapat hubungan antara sapa orang tua dengan pengetahuan remaja tentang kesehatan reproduksi remaja di SMP Negeri 28 Batam Kelurahan Belian Kecamatan Batam Kota Kota Batam Tahun 2018.

Hasil penelitian ini didukung dengan penelitian terkait yang pernah dilakukan oleh Ardhiyanti Yulrina tentang Pengaruh Peran Orang Tua terhadap Pengetahuan Remaja tentang Kesehatan Reproduksi di SMA Negeri Se-Kota Pekanbaru kelas X dan XI Tahun 2013". Dari hasil analisis multivariat, variabel yang berhubungan secara signifikan adalah variabel peran orang tua dalam hal ini adalah komunikasi orang tua. Nilai OR dari variabel peran orang tua adalah 1,982 artinya remaja yang orang tuanya tidak berperan berisiko 2 kali memiliki pengetahuan tentang kesehatan reproduksi yang kurang baik dibanding remaja yang orang tuanya berperan. Sedangkan menurut hasil penelitian Rizka Kurniawati, Heny Setyowati ER, Mahmudah. Hubungan Komunikasi Antara Orang 
Tua-Anak Remaja Dengan Kesehatan Reproduksi Dengan Perilaku Seks Pranikah Di SMA Negeri 1 Salaman Kabupaten Magelang Tahun 2010. Terdapat hubungan komunikasi orang tua dan anak remaja tentang kesehatan reproduksi remaja dengan perilaku seks pranikah. Dengan $p$ value $=$ 0,011 .

Kekuatan korelasi pada hasil penelitian ini adalah 0,584 yang menunjukan ada hubungan yang kuat antara sapa orang tua dengan pengetahuan remaja tentang kesehatan reproduksi remaja di SMP Negeri 28 Batam Kelurahan Belian Kecamatan Batam Kota Kota Batam Tahun 2018. Hasil penelitian ini menunjukan bahwa remaja yang memiliki sapa orang tua yang baik dalam memberikan bekal pengetahuan tentang kesehatan reproduksi maka berpengaruh terhadap pengetahuan remaja tersebut. Jika sapa orang tua yang baik maka akan muncul pengetahuan remaja tentang kesehatan reproduks yang baik sehingga dapat memberikan pencegahan pada anak terhadap dampak negatif dari kesehatan reproduksi dalam menciptakan rasa nyaman, memberikan perlindungan agar terhindar dari bahaya akan masa depannya sendiri. Apabila anak memperoleh informasi dengan benar dan tepat tentang kesehatan reproduksi khususnya mengenai seksualitas, maka anak tidak lagi mempunyai keinginan yang berlebihan untuk menyalurkan dorongan seksualnya dengan perilaku yang negatif. Oleh karena itu seharusnya orang tua memberikan pemahaman sedini mungkin sesuai dengan umur anak, menjalin kedekatan dengan anak dan menentukan kapan waktu yang tepat untuk memberikan pengetahuan tentang kesehatan reproduksi sehingga informasi yang diperoleh merupakan yang pertama sebelum anak mendapatkannya dari sumber informasi yang lain. Dalam hal ini mengembangkan hubungan yang terbuka antara orang tua dan anak sehingga dapat menghindarkan anak dari perasaan malu dan segan saat membicarakan masalah yang berhubungan dengan kesehatan reproduksi.

Arah korelasi penelitian ini adalah positif $(+)$ sehingga semakin baik sapa orang tua terhadap remaja, maka semakin baik pengetahuan remaja tentang kesehatan reproduksi remaja di SMP Negeri 28 Batam Kelurahan Belian Kecamatan Batam Kota Kota Batam Tahun 2018.

\section{KESIMPULAN}

Berdasarkan hasil penelitian diperoleh kesimpulan sebagai berikut :Diperoleh lebih dari separuh sapa orang tua pada anak remaja baik sebanyak 113 responden $(72,4 \%)$ dari total 156
responden.Diperoleh lebih dari separuh pengetahuan remaja tentang kesehatan reproduksi remaja baik sebanyak 94 responden $(60,3 \%)$ dari total 156 responden.Adanya hubungan sapa orang tua dengan pengetahuan remaja tentang kesehatan reproduksi remaja di SMP Negeri 28 Batam dengan $p$ value $=0,000$ lebih kecil dari nilai a 0,05 . Hasil penelitian dari uji chi-square danya didapat nilai $p$ value $=0,000$ lebih kecil dari nilai a 0,05. Artinya terdapat hubungan sapa orang tua dengan pengetahuan remaja tentang kesehatan reproduksi remaja di SMP Negeri 28 Batam hubungan sapa orang tua dengan pengetahuan remaja tentang kesehatan reproduksi remaja di SMP Negeri 28 Batam.

\section{SARAN}

Hasil penelitian diharapkan dapat memberikan informasi untuk membekali orang tua agar orang tua dapat meningkatkan komunikasi sehingga dapat memberikan informasi yang tepat bagi anak remaja terutama pengetahuan tentang kesehatan reproduksi.

\section{DAFTAR PUSTAKA}

Asna, K. (2011). Hubungan Antara Pengetahuan Dan Sikap Terhadap Kesehatan Reproduksi Dengan Perilaku Seksual Pra Nikah Pada Siswa Di Sma Negeri 14 Kota Semarang Tahun Ajaran 2010/2011.

Badan Kependudukan dan Keluarga Berencana Nasional. Survey Sosial Ekonomi Nasional 2015.

Badan Pusat Statistik. https://microdata.bps.go.id/mikrodata/index.p $\mathrm{hp} /$ catalog/769. Diperoleh pada tanggal 31 Agustus 2018.

Data Sekolah SMP Negeri 28 Batam (2018). Profil Sekolah

Dinas Pendidikan Kota Batam. Data Jumlah dan Rombel Siswa SMP Negeri dan Swasta Kota Batam Tahun 2017.

Erlin, Y. (2017). Analisis siswa terhadap pemilihan jajanan sekolah. Retrieved from http://repository.ump.ac.id/4114/3/Erlin Yuliana_BAB II.pdf

Kumalasari, A. (2012). Kesehatan Reproduksi Untuk Mahasiswa Kebidanan dan Keperawatan. Jakarta: Salemba Medika.

Kurniawati, R. (2012). Hubungan Antara Komunikasi Orang Tua-Anak Remaja Tentang Kesehatan Reproduksi Dengan Perilaku Seks Pranikah Di SMA Negeri 1 Salaman Kabupaten Magelang. h. Retrieved from 
ttp://jurnal.unimus.ac.id/index.php/psn12012 010/article/view/1295

Kusmiran. (2012). Kesehatan Reproduksi Remaja Dan Wanita. Penerbit: Salemba Medika, Jakarta. Jakarta: Salemba Medika.

Miftakhul Muslichah. (2008). Pengaruh Hubungan Orangtua dan Anak Remaja terhadap Pengetahuan Sikap Perilaku tentang Seks Bebas dan Narkoba.

Putra, M. P. (2014). Hubungan Antara Peran Keluarga Dengan Perilaku Seksual Pranikah Pada Remaja SMA/Sederajat Di Wilayah Kerja Puskesmas Sukawati I.

Rahma. (2016). Gambaran Tingkat Pengetahuan Remaja Tentang Kebersihan Organ Genetalia EKsterna Di SMAN 90 Jakarta. Retrieved from http://repository.uinjkt.ac.id/dspace/bitstream /123456789/32157/1/ALLAILY AMALIA RACHMA-FKIK.pdf

Ririn Darmasih. (2009). Faktor yang Mempengaruhi Perilaku Seks PranikahPada Remaja Di Surakarta. Retrieved from Eprints.Ums.Ac.Id

Rohmaniyah, S. I. (2014). Gambaran Dan Pengetahuan Sikap dan Gambaran Remaja Puteri Dalam Menghadapi Perubahan Fisik Saat Pubertas Di Pondok Pesantren AlBaqiyahtussholihat. Retrieved from https://media.neliti.com/media/publications/1 25724-ID-none.pdf

Rumengan. (2010). Metodologi Penelitian dengan
SPSS. Batam: Uniba Press.

Septiana. (2014). Pengaruh Pendidikan Kesehatan Terhadap Tingkat Pengetahuan Remaja Tentang Kesehatan Reproduksi di SMP Ruhma Ciputat. Retrieved from http://repository.uinjkt.ac.id/dspace/bitstream /123456789/25662/1/Septiana - fkik.pdf.

Soetjiningsih. (2010). Tumbuh Kembang Remaja dan Permasalahannya. Jakarta: Sagung Seto.

Th. Purwoastuti, W. (2015). Komunikasi dan Konseling Kebidanan. Yogyakarta.: Pustaka Baru Press.

Ulfa. (2017). Peran Orang Tua Dalam Pendidkan Kesehatan Reproduksi Remaja Kelas VII Di SMP Muhammadiyah Mlati Sleman. Retrieved from http://repository.unjaya.ac.id/2190/2/ULFAN URULHAYAH ROHMATIKA 1113019 nonFULL.pdf

Wardana Indra dk. (2015). Kurikulum Diklat Tenkis Pengelola PIK Remaja/Mahasiswa. Jakarta: Badan Kependudukan dan Keluarga Berencana Nasional.

Yulrina Ardhiyanti. (2013). Pengaruh Peran Orang Tua terhadap Pengetahuan Remaja tentang Kesehatan Reproduksi Remaja. Retrieved from

jurnal.htp.ac.id/index.php/keskom/article/dow nload/57/45/ 